
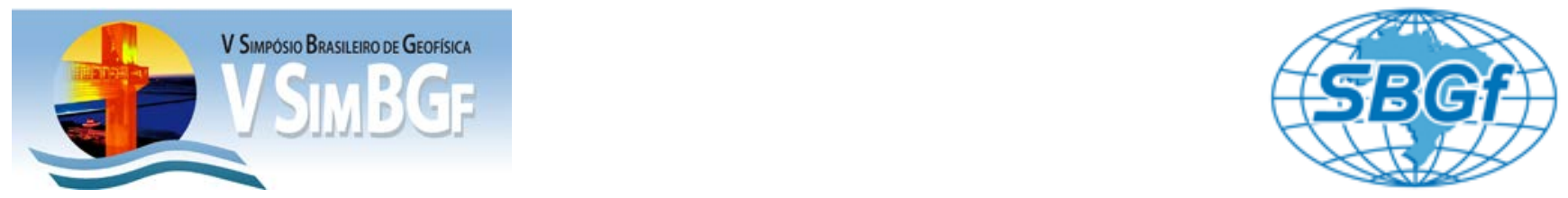

\title{
Levantamento magnetométrico na região do Passo do Rocha, Município de Vila Nova do Sul - RS. Resultados preliminares
}

Kathlem de Melo Teixeira, Lucas Freitas Mota, Renata da Silva Pereira, Letícia Borges de Almeida, Maximilian Fries, Marcus Remus*, Ildo Panow* e Thamy Lara de Sousa*.

Universidade Federal do Pampa - UNIPAMPA

Universidade Federal do Rio Grande do Sul - URGS

Copyright 2012, SBGf - Sociedade Brasileira de Geofísica

Este texto foi preparado para a apresentação no V Simpósio Brasileiro de Geofísica, Salvador, 27 a 29 de novembro de 2012. Seu conteúdo foi revisado pelo Comitê Técnico do $V$ SimBGf, mas não necessariamente representa a opinião da SBGf ou de seus associados. É proibida a reprodução total ou parcial deste material para propósitos comerciais sem prévia autorização da SBGf.

\section{Resumo}

Este estudo apresenta os resultados preliminares de uma aquisição Geofísica, método da magnetometria, realizada no Estado do Rio Grande do Sul - Brasil. Rochas do Complexo Cambaí (ultramafitos), determinação dos limites laterais e em profundidade justificam o estudo na área proposta. A aplicação de métodos geofísicos como a magnetometria constituem uma ferramenta valiosa para a detecção, análise e compreensão das estruturas litologias e suas variações mineralógicas. A posterior aplicação de mapas geofísicos e modelagens em conjunto com estudos prévios em parceria com outros pesquisadores e universidades possibilitam a formulação de hipóteses e teorias a cerca da evolução geológica e tectônica ocorrida na região.

\section{Introdução e Objetivos}

Um levantamento magnetométrico terrestre, em escala de detalhe, proporciona informações necessárias para formular hipóteses, criar, confirmar e/ou refinar modelos propostos buscando, desta maneira, a localização de eventuais estruturas, as quais poderiam contribuir para a determinação dos processos evolutivos que ocorreram na área de estudo. A magnetometria terrestre, associada a informações geológico-estruturais já existentes da área, fornece subsídios para o refinamento de modelos de gênese, concentração e formação das mineralizações na área. As principais etapas de desenvolvimento deste estudo em fase preliminar são:

- Levantamento bibliográfico, digitalização e geração de mapas;

- Levantamento magnetométrico terrestre;

- Processamento dos dados (geração de um grid);

- Mapa de isovalores com os valores magnetométricos de campo total;

- Determinação dos principais gradientes horizontais (anomalias) e sua correlação com as litologias, lineamentos e estruturas na área.

\section{Localização da Área}

A área de estudo localiza-se na região sudoeste do Estado do Rio Grande do Sul, próximo ao município de Vila Nova do Sul e dista aproximadamente $300 \mathrm{~km}$ de Porto Alegre e situa-se entre os municípios de São Sepé, São Gabriel e Caçapava do Sul (Figura 1).
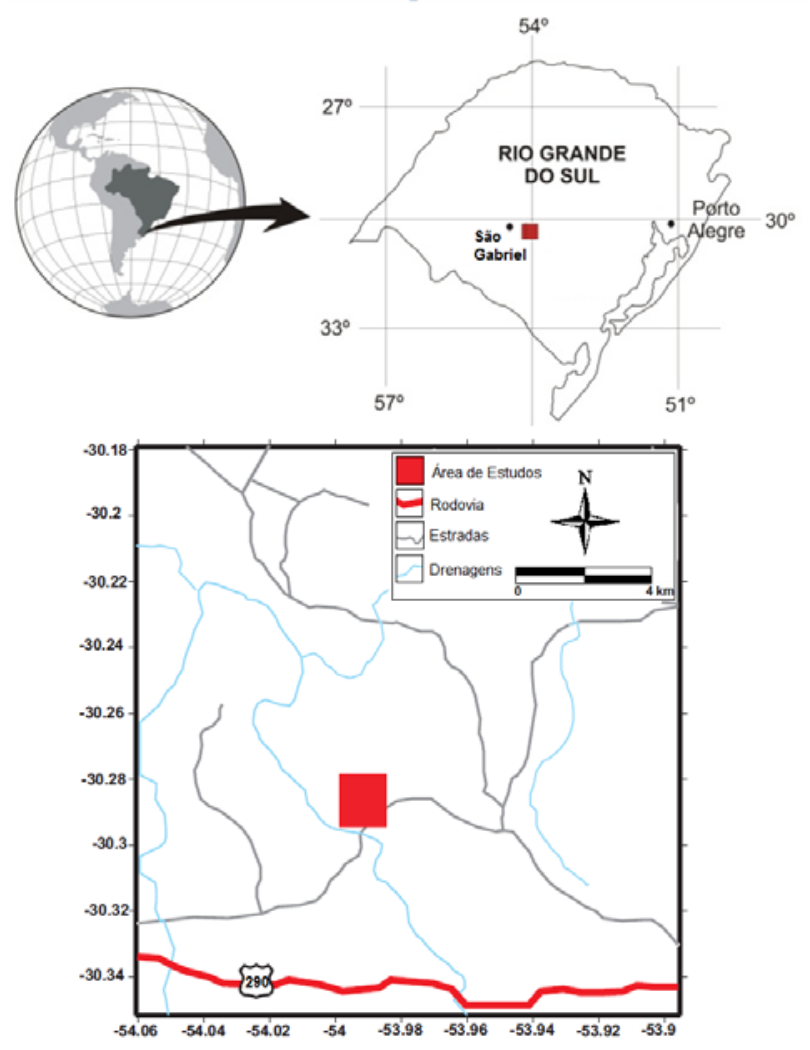

Figura 1 - Mapa de localização da área de estudos, principais estradas e acessos.

\section{Contexto Geológico Regional e Local}

Regionalmente a área é representada pelo Complexo Cambaí constituída por metaultramafitos representados por harzburgitos, que ocorrem como lentes decamétricas imersas em serpentinitos e xistos magnesianos PORCHER (2000). O Complexo Cambaí é composto por um grande volume de rochas plutônicas juvenis, como 
gnaisses dioríticos e tonalíticos, meta-dioritos, metatonalitos, truncados por várias gerações de plútons de dioritos a granodioritos e corpos tabulares e veios de trondhjemitos, e pegmatitos de composição quartzofeldspática variada. A composição química dessas rochas indica um ambiente de arco magmático de margem continental. Este complexo é proveniente do evento Orogênico São Gabriel ocorrido no Ciclo Brasiliano. Formação Rio Bonito de idade $430 \mathrm{Ma}$ é constituída por espessos bancos de arenitos quartzofeldspáticos, esbranquiçados, amarelos e róseos (freqüentemente ferruginosos) e siltitos, que se intercalam com camadas de folhelhos pretos (carbonosos), cinzentos, ou claros, e com camadas de carvão.

A Formação Palermo (Pp) de idade $430 \mathrm{Ma}$, localiza-se em alguns locais da porção leste da Folha Cachoeira do Sul (CPRM, 2000), em que assenta diretamente sobre o embasamento, apresenta contatos concordantes, freqüentemente com feições erosivas, com a sequência sedimentar da Formação Rio Bonito, principalmente quando sua seção basal se encontra sobreposta a camadas de carvão e de siltitos carbonosos.

Seu intervalo basal é constituído predominantemente por siltitos e arenitos muito finos interlaminados, apresentando como estruturas sedimentares laminação ondulada.

A sedimentação Palermo se desenvolveu em um ambiente marinho de plataforma rasa, segundo Porcher, (2000). São depósitos aluvionares atuais e subatuais de areia, cascalho imaturo, mal classificado, ao longo de calhas dos cursos de água. Areia fina, siltes e argilas orgânicas nas planícies aluviais.

No contexto Geológico Local, a geologia da área situada nas imediações do arroio cambai, segundo Remus (1990) compreende um conjunto de litologias de composição e origem diversas, metamorfisadas e polideformadas que representam o embasamento Précambriano desta região.

Este conjunto de rochas é constituído por uma associação supracrustal "gnaissificada" dominante sedimentar clástica, contendo intercalações de rochas maficas e ultramáficas intrudidos por magmas de composição variável desde granodioritos até sienogranitos.

Nessa associação supracrustal, aqui designada distinguem-se duas sequências rochosas: a sequência meta-sedimentar, composta por gnaisses quartzofeldspaticos dominates, derivados de pelitos e semipelitos com intercalações de anfibolitos listrados e subordinadamente quartzitos. Como também a sequencia máfica-ultramáfica constituída por xistos magnesianos variados, serpentinitos, anfibolitos e metagabros, intercalados na sequencia meta-sedimentar na forma de horizontes concordantes com a foliação principal.

Remus (1990) indica que as unidades litológicas da sequencia mafica-ultramafica ocorrem na forma de jazimentos estratificados na sequencia meta-sedimentar em várias escalas. Os serpentinitos ocorrem como camadas e/ou lentes alongados entremeadas na sequencia do complexo cambai. Estes metamorfitos hidratados possuem dimensões que não ultrapassam a 400 metros de comprimento e 70 metros de largura aflorante , tendo como encaixante os xistos magnesianos e/ou tabulares e encaixadas nos meta sedimentos.

Devido a resistência aos processos de intemperismo, os serpentinitos ocorrem como cristas alongadas formadas por uma série de blocos de dimensões centimétricas à métricas irregulares. O grau de serpentinização é bastante intenso e a olivina é raramente preservada nas ocorrências maiores, sendo possível a sua observação nos jazimentos de menor expressão.

Os xistos magnesianos predominam sobre os outros tipos litológicos da sequencia máfica-ultramáfica, compreendendo a maior expressão em área aflorante de rochas ultramáficas na região de estudo. Constituem camadas e/ou lentes homogêneas intercaladas na sequencia meta-sedimentar ou encontram-se associados aos anfibolitos e sedimentos químicos (formações ferríferas) ou as bordas de serpentinitos (Figura 2).
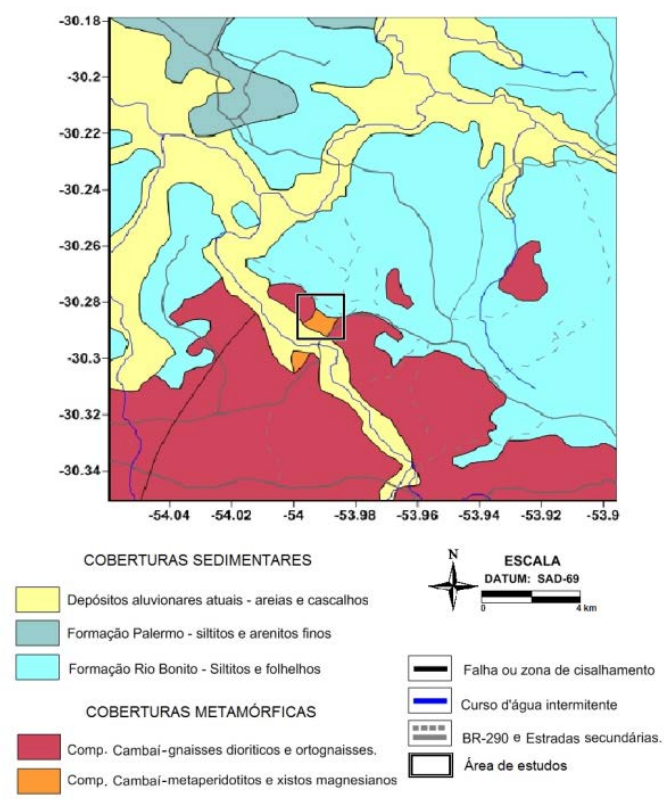

Figura 2.Contexto geológico da região, e a área de estudos. Modificado de CPRM (1995).

\section{Metodologia}

Foram adquiridas, até o momento 269 estações magnetométricas terrestres. As leituras magnéticas das estações levantadas foram obtidas através de dois magnetômetro de precessão de prótons da GEM Systems Inc, modelo GSM - 19. Usou-se um espaçamento médio de vinte e cinco metros entre os pontos ao longo de doze perfis de caminhamento. O georeferenciamento dos pontos foram determinadas por meio de um GPS portátil de mão (Figura 3). Os dados adquiridos foram submetidos a correção diurna para obtenção dos valores do campo magnético anômalo total. 


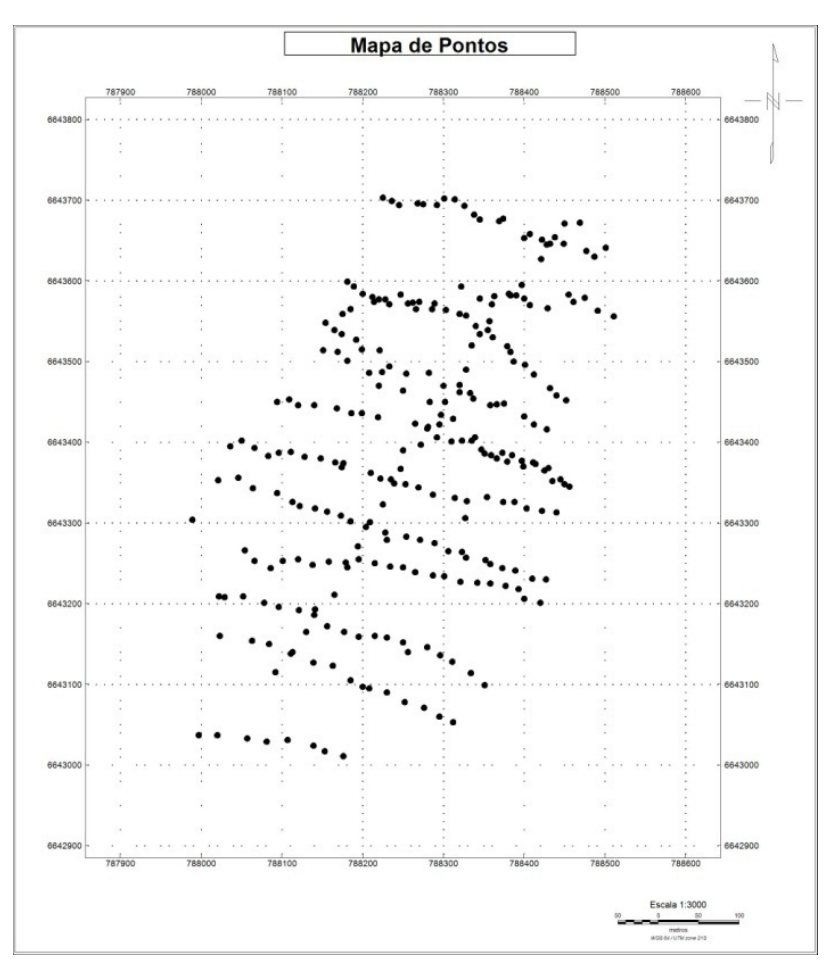

Figura 3. Mapa de pontos com as estações magnetométricas na área de estudos adquiridas até o presente momento.

\section{Características do mapa magnetométrico de campo total}

O mapa magnetométrico com os valores de campo anômalo total (Figura 4) é produto de um grid gerado por interpolação pelo método da mínima curvatura. O grid é composto por $70 \times 64$ pontos (direções $X$ e $Y$ respectivamente), com tamanho de célula de 12,5 metros. Os valores que compõem o grid permitem a geração de um mapa de cores sombreado com os respectivos isovalores das anomalias magnéticas apresentadas.

A base de dados formada ao longo dos levantamentos, valores das estações magnetométricas, coordenadas, dados das anomalias magnéticas e o mapa de contorno, foram elaborados por rotinas próprias no software OASIS/MONTAJ comercializado pela Geosoft Inc.

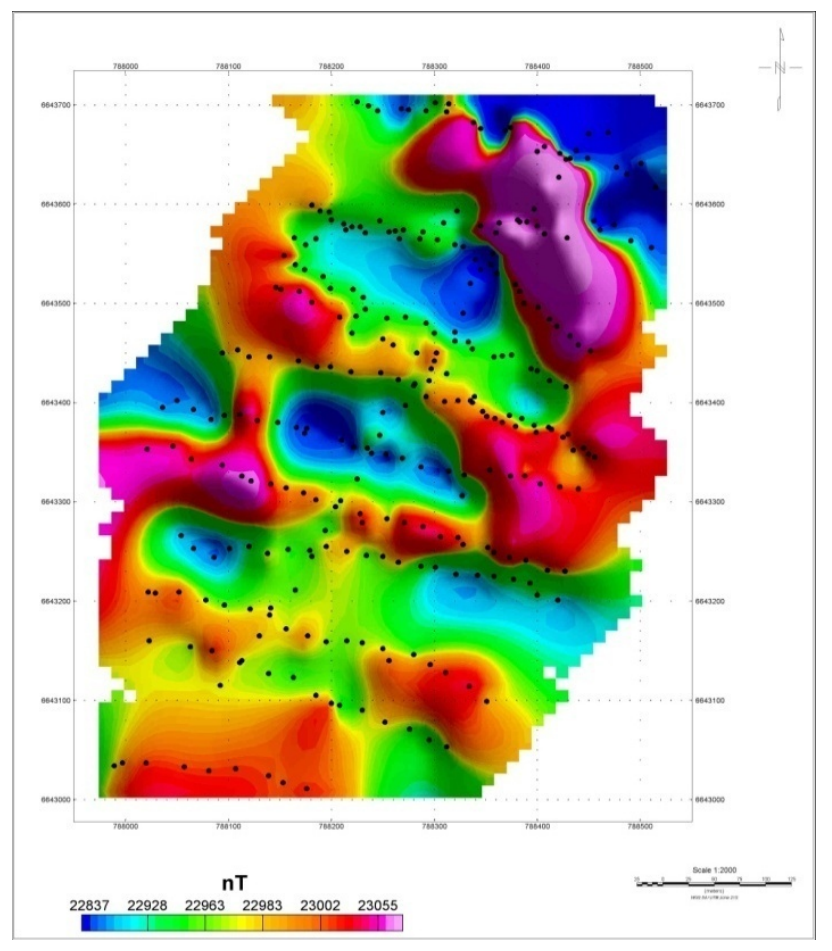

Figura 4. Mapa de contorno sombreado com os dados magnéticos anômalos de campo total.

\section{Discussão e Conclusões}

Os mapas gerados das anomalias magnéticas de campo total, permitem diferenciar, de forma preliminar, as anomalias magnéticas relacionadas as litologias com altas susceptibilidade magnética e oriundas de fontes rasas e profundas. A pouca densidade de estações magnetométricas adquiridas até o momento, permite uma correlação com as litologias predominantes da área (serpentinitos e encaixantes xistos e gnaisses) e de sua variação e contraste lateral e, também, em profundidade. $\mathrm{O}$ estudo preliminar magnetométrico demontra-se eficaz na determinação e delineação das principais fontes magnéticas observadas na região proposta para o estudo. Essas variações são um produto das estruturas, litologias e eventuais mineralizações presentes em diferentes níveis de investigação na área proposta. Aplicando-se posteriormente, diferentes técnicas de processamento, um maior adensamento das estações a formulação e geração de geofísicos/geológicos/estruturais para a área.

\section{Agradecimentos}

Os autores agradecem ao professor doutor Maximilian Fries do Curso de Geofísica da Universidade Federal do Pampa - Campus Caçapava do Sul, pelo auxílio prestado durante as primeiras aquisições magnetométricas de campo na área estudada, ao engenheiro cartográfico lldo Parnow, geóloga Thamy Lara de Sousa e professor Dr. 
Marcus Remus, pela contribuição na aquisição de dados e conhecimento científico da região.

\section{Referências}

GEOSOFT INCORPORATED. 1999. Montaj MAGMAP filtering; 2 - D frequency domain of potential field data extension for Oasis Montaj v.6.1. Toronto, Ontario, Canadá.

BORBA, A.W.; MIZUSAKI, A.M.P.; SILVA, D.R.A.; KOESTER, E.; NORONHA, F.L.; CASAGRANDE, J. Provenance of the Neoproterozoic Maricá Formation (Sulrio-grandense Shield, southern Brazil): petrographic and $\mathrm{Sm}-\mathrm{Nd}$ isotopic constraints. (2006) Gondwana Research, v. 9 (4), pp. $464-474$.

REMUS, MARCUS V. D. Geologia e Geoquímica do Complexo Cambaizinho, São Gabriel-RS. 1990. 291 pg. Tese de doutorado - Universidade Federal do Rio Grande do Sul Curso de Pós-Graduação em Geociências. Porto Alegre, 1990.

CPRM (Serviço Geológico do Brasil). Mapa geológico do Brasil. In: Geologia, Tectônica e Recursos Minerais do Brasil: Sistema de Informações Geográficas - SIG e Mapas na escala 1:2.500.000. (2000).

CPRM Folha Cachoeira SH-22-Y-A, Escala 1:50.000. Programa Levantamentos Geológicos Básicos do Brasil, Brasília, 339 p. (1995).

PORCHER, C. A.; LOPES, R. C.. Relatório folha Cachoeira do Sul SH.22 - Y - A: 2000a. Porto Alegre. $147 p$.

PORCHER, C. A.; LOPES, R. C. Cachoeira do Sul, folha SH.22 - Y - A. Porto Alegre: CPRM, Programas Levantamentos Geológicos Básicos do Brasil, 2000b. Escala 1: 250.000. 